\title{
Evaluation of a portable device for diagnosing the sleep apnoea/hypopnoea syndrome
}

\author{
K. Dingli, E.L. Coleman, M. Vennelle, S.P. Finch, P.K. Wraith, T.W. Mackay, N.J. Douglas
}

Evaluation of a portable device for diagnosing the sleep apnoealhypopnoea syndrome. K. Dingli, E.L. Coleman, M. Vennelle, S.P. Finch, P.K. Wraith, T.W. Mackay, N.J. Douglas. C ERS Journals Ltd 2003.

ABSTRACT: Waiting times for hospital-based monitoring of the obstructive sleep apnoea/hypopnoea syndrome (OSAHS) are rising. This study tested whether Embletta, a new portable device, may accurately diagnose OSAHS at home.

A synchronous comparison to polysomnography was performed in $\mathbf{4 0}$ patients and a comparison of home Embletta studies with in-laboratory polysomnography was performed in 61 patients.

In the synchronous study, the mean difference (polysomnography-Embletta) in apnoeas+hypopnoeas $(\mathrm{A}+\mathrm{H}) \cdot \mathrm{h}^{-1}$ in bed was $2 \cdot \mathrm{h}^{-1}$. In comparison to the apnoea/ hypopnoea index $(\mathrm{AHI}) \cdot h^{-1}$ slept, the Embletta $(\mathrm{A}+\mathrm{H}) \cdot h^{-1}$ in bed differed by $8 \cdot h^{-1}$. These data were used to construct diagnostic categories in symptomatic patients from their Embletta results: "OSAHS" $\left(\geqslant 20(A+H) \cdot h^{-1}\right.$ in bed $)$, "possible OSAHS" (10-20 $(A+H) \cdot h^{-1}$ in bed) or "not OSAHS" $\left(<10(A+H) \cdot h^{-1}\right.$ in bed $)$. In the home study, the mean difference in $(A+H) \cdot h^{-1}$ in bed was $3 \cdot h^{-1}$. In comparison to the polysomnographic $\mathrm{AHI} \cdot \mathrm{h}^{-1}$ slept, the Embletta $(\mathrm{A}+\mathrm{H}) \cdot \mathrm{h}^{-1}$ in bed differed by $6 \pm 14 \cdot \mathrm{h}^{-1}$. Using the above classification, all nine patients categorised as not OSAHS had AHI $<15 \cdot h^{-1}$ slept on polysomnography and all 23 with OSAHS on Embletta had an AHI $\geqslant 15$ on polysomnography, but 18 patients fell into the possible OSAHS category potentially requiring further investigation and $\mathbf{1 1}$ home studies failed.

Most patients were satisfactorily classified by home Embletta studies but 29 out of 61 required further investigation. The study suggested a $42 \%$ saving in diagnostic costs over polysomnography if this approach were adopted.

Eur Respir J 2003; 21: 253-259.
Obstructive sleep apnoea/hypopnoea syndrome (OSAHS) affects $1-4 \%$ of the population [1] causing daytime sleepiness, impaired work performance, road accidents [2] and hypertension [3]. OSAHS is classically diagnosed by in-laboratory overnight sleep recording: polysomnography [4]. However, the limited number of sleep centres and beds often results in long waiting lists for diagnosis and treatment of OSAHS and there is evidence that untreated sleep apnoea is both deleterious to the patient and expensive to the healthcare budget $[5,6]$. Home-based sleep studies have potential advantages in terms of decreased costs [7], including no charges for hospital accommodation, convenience, as well as possibly improved sleep quality for the patients. A recent study, comparing the sleep quality of in-laboratory sleep studies to home-based studies, showed better sleep efficiency, more time spent in rapid eye movement and slow wave sleep, and significantly fewer arousals during the home-based studies [8].

The present study aims to examine the diagnostic accuracy of a new portable device, the Embletta (Flaga, Reykjavik, Iceland).
Sleep Centre, Royal Infirmary NHS Trust, Edinburgh, Scotland, UK.

Correspondence: N.J. Douglas Dept of Medicine

Royal Infirmary NHS Trust

Lauriston Place

Edinburgh

EH3 9YW

Scotland

UK

Fax: 441315363255

E-mail: n.j.douglas@ed.ac.uk

Keywords: Limited home studies sleep apnoea diagnosis

Received: November 272001

Accepted after revision: May 32002

\section{Subjects}

All study patients referred to the sleep centre with possible OSAHS had either self-reported daytime sleepiness (Epworth Sleepiness Scale $>10$ ) or two other major symptoms of OSAHS [9], and gave written informed consent to participate in the study, which had the approval of the Local Ethics Committee. The only exclusion criteria were living $>50$ miles from 
the sleep centre and immobility, both of which excluded patients from the home study only.

During the synchronous trial, 40 consecutive patients (33 male, age $46 \pm 10$ yrs (mean \pm SD), body mass index (BMI) $32 \pm 6 \mathrm{~kg} \cdot \mathrm{m}^{-2}$ ) underwent a simultaneous sleep study with the portable device and in-lab diagnostic polysomnography (Compumedics, Abbotsford, Australia). Both were applied to the patients by trained sleep technicians.

During the home trial, 61 consecutive patients (47 male, age $50 \pm 11 \mathrm{yrs}, \mathrm{BMI} 31 \pm 6 \mathrm{~kg} \cdot \mathrm{m}^{-2}$ ) were studied during two different nights, in random order and within a time interval of 2-40 days. Patients were educated by a trained technician on the application of the portable diagnostic device, which took on average $20 \mathrm{~min}$. They then took the device home with written instructions and applied the sensors unsupervised. The device was returned the next day and the data were analysed.

\section{Nocturnal measurements}

The portable, limited sleep study performed with the Embletta device, consisted of the following: 1) nasal pressure detector using nasal cannulae/pressure transducer system, recording the square root of pressure as an index of flow; 2) thoraco-abdominal movement detection through two piezoelectric belts; 3) finger pulse oximeter; and 4) body position detection. Polysomnography was performed with the authors' standard techniques [10], using a computerised recording system (Compumedics, Abbotsford, Australia) consisting of: 1) sleep monitoring through two frontal unipolar, unilateral (FP1-LEOG, FP2-REOG) and a bipolar central/occipital (CZ-PZ) electroencephalogram tracing, two outer canthi electrodes and bilateral submental electromyogram (EMG); 2) bilateral tibial EMG and a body position detector; 3) three-lead electrocardiogram; and 4) respiration monitoring through a thermistor sensor for apnoea detection, two inductance plethysmographic belts for the thoraco-abdominal movement detection, a digital microphone for snoring detection and a pulse oximeter (Ohmeda Biox 3700, Louisville, CO, USA).

\section{Off-line analysis}

Each patient's two studies were scored by the same observer. However, the observer was always blind to the patient's identity and the studies were batched to ensure the scorer could not identify the pairs of studies belonging to the same subject. Sleep was scored according to the RECHTSCHAFFEN and KALES criteria [11].

Apnoeas were defined as complete cessation of airflow and hypopnoeas as a reduction in thoracoabdominal movement $\geqslant 50 \%$ for $\geqslant 10 \mathrm{~s}$ [4]. During the synchronous validation studies, hypopnoeas on the Embletta device were additionally scored during a separate session as a reduction in the nasal pressure amplitude of $\geqslant 50 \%$ for $\geqslant 10 \mathrm{~s}$ [12].

Two apnoea/hypopnoea measures were calculated from each polysomnogram: one from the division of the number of apnoeas and hypopnoeas after sleep onset by the total sleep time (TST) yielding apnoea/ hypopnoea index (AHI); the other from the division of the total number of apnoeas and hypopnoeas by the hours in bed $\left((\mathrm{A}+\mathrm{H}) \cdot \mathrm{h}^{-1}\right.$ in bed $)$. As the portable device does not record sleep, study onset was marked as soon as respiration settled down to a rhythmic, stable pattern. The end of the study was set either according to the information given by the patient as to the time of morning awakening or based on the quality of the tracings and regularity of breathing pattern.

The limited studies during the synchronous in-lab trial yielded three $\mathrm{A}+\mathrm{H}$ measures. One $(\mathrm{A}+\mathrm{H}) \cdot \mathrm{h}^{-1}$ in bed was based on manual scoring of changes in nasal pressure and thoraco-abdominal movement $(\mathrm{A}+\mathrm{H}$ $\mathrm{ma}$ ), the other on manual scoring of changes in nasal pressure alone $(\mathrm{A}+\mathrm{H} \mathrm{fl})$ and the third was from the automated software analysis $(\mathrm{A}+\mathrm{H}$ au). The limited home studies yielded two measures: $\mathrm{A}+\mathrm{H}$ ma and $\mathrm{A}+\mathrm{H}$ au.

\section{Statistical analysis}

The diagnostic accuracy and reproducibility of the patients' classification into no OSAHS, possible and definite OSAHS based on the portable study outcomes was assessed through kappa statistics, which evaluated the agreement between polysomnography and portable Embletta recording system, based on the different scoring criteria. Bland and Altman plots were generated to demonstrate the degree of identity between the outcomes of the two diagnostic methods, taking into consideration the different scoring criteria of the limited study data. Pearson's correlation analysis evaluated the significance of agreement in the $\mathrm{A}+\mathrm{H}$ score between the two methods. Paired samples t-test was performed to evaluate differences in the outcomes across the subjects due to the different scoring criteria used. Tests were two-tailed and $\mathrm{p}<0.05$ was accepted as statistically significant. Data are presented as mean \pm SD unless otherwise stated.

\section{Results}

\section{Recording adequacy}

Synchronous study. Of the 40 patients, one was excluded from the data comparison due to technical problems, as the Embletta only recorded $3 \mathrm{~min}$ of interpretable data.

The mean sleep efficiency of the remaining 39 patients $\left(32\right.$ male, $46 \pm 9 \mathrm{yrs}, 32 \pm 6 \mathrm{~kg} \cdot \mathrm{m}^{-2}$ ) was $76 \pm 2 \%$ (mean \pm SEM) of the sleep period time (SPT). Mean TST was $5.1 \pm 0.3 \mathrm{~h}$ (mean \pm SEM). The mean AHI of the patients was $35 \cdot \mathrm{h}^{-1}$ sleep (table 1 ).

A further three patients were excluded from the comparison between nasal pressure based hypopnoea scoring versus scoring based on thoraco-abdominal movement and nasal pressure changes, due to technical 
Table 1. - Polysomnography and limited Embletta studies during the validation study

\begin{tabular}{lcccrrr}
\hline Patient group & Patients $n$ & PSG $h$ & Emb h & PSG:AHI & PSG:A+H & Emb:A+H \\
\hline PSG:AHI & 39 & $6.8 \pm 0.3$ & $6.9 \pm 0.3$ & $35.4 \pm 5.5$ & $29.2 \pm 3.7$ & $27.2 \pm 3.4$ \\
AHI $<10$ & 6 & $6.5 \pm 1.1$ & $6.7 \pm 1.1$ & $5.3 \pm 0.9$ & $6.3 \pm 1.0$ & $6.3 \pm 1.0$ \\
$10 \leqslant$ AHI $<20$ & 12 & $6.6 \pm 0.6$ & $6.7 \pm 0.6$ & $13.8 \pm 0.7$ & $13.7 \pm 0.8$ & $14.2 \pm 1.7$ \\
AHI $\geqslant 20$ & 21 & $7.0 \pm 0.4$ & $7.1 \pm 0.4$ & $56.3 \pm 7.7$ & $44.6 \pm 4.7$ & $40.7 \pm 4.6$ \\
\hline
\end{tabular}

Data are presented as mean \pm SEM. PSG: polysomnography; Emb: Embletta; AHI: apnoea/hypopnoea index; A+H: apnoea+hypopnoea.

problems in the nasal pressure recordings. In two of these patients the nasal pressure tracing did not record and in one patient it was not interpretable.

Home study. Inadequate recordings were obtained at home in 11 of the 61 patients. One was due to the patient not using the equipment at all, five due to technical problems with the equipment (plugging, batteries or software) and in five no reason was identified. This overall fail rate of $18 \%$ contained a learning effect; the fail rate in the latter two-thirds of the study was $12 \%$ (five from 42 studies). Fifty patients then studied in the sleep centre had a mean sleep efficiency of $82 \pm 1 \%$ (mean \pm SEM) of the SPT. Mean TST of the in-lab recordings was $6.4 \pm 0.1 \mathrm{~h}$ (mean \pm SEM), the better sleep quality reflecting the lower number of sensors than in the synchronous study. Mean AHI was $29 \cdot \mathrm{h}^{-1}$ sleep (table 2 ).

\section{Diagnostic accuracy}

Synchronous study. The mean difference (polysomnography-Embletta) in $(\mathrm{A}+\mathrm{H}) \cdot \mathrm{h}^{-1}$ in bed was $2 \pm 5 \cdot \mathrm{h}^{-1}$ (fig. $1 \mathrm{a}$ and $\mathrm{b} ; \mathrm{p}=0.02$ ) with a close correlation between the results of the two studies ( $\mathrm{rho}=0.98, \mathrm{p}<0.001$ ). Automatic Embletta scoring produced a mean difference from the polysomnography of $0.1 \cdot \mathrm{h}^{-1}$ in bed, but a larger variance (SD $15 \cdot \mathrm{h}^{-\mathrm{P}}$ in bed).

In comparison to the $\mathrm{AHI} \cdot \mathrm{h}^{-1}$ slept, the Embletta $(\mathrm{A}+\mathrm{H}) \cdot \mathrm{h}^{-1}$ in bed differed by a mean of $8 \pm 16 \cdot \mathrm{h}^{-1}$ (fig. $1 \mathrm{c}$ and $\mathrm{d}$ ), but those with $>40 \cdot \mathrm{h}^{-1}$ in bed on both methods were excluded, the mean difference was $2 \pm 5 \cdot h^{-1}$. Hypopnoea scoring based on nasal pressure changes alone was evaluated through comparison between polysomnographic outcomes $\left((\mathrm{A}+\mathrm{H}) \cdot \mathrm{h}^{-1}\right.$ in bed) and Embletta $\mathrm{A}+\mathrm{H}$ fl outcomes. The mean difference of (polysomnography-Embletta) in $(\mathrm{A}+\mathrm{H}) \cdot \mathrm{h}^{-1}$ in bed was $3 \pm 9 \cdot h^{-1}(p=0.004$; fig. 1e and $\mathrm{f}$.

The difference between outcomes based on the two hypopnoea definitions used (combined nasal pressure and thoraco-abdominal movement changes versus changes in nasal pressure alone) was not significant across the 36 patients $(\mathrm{p}=0.4)$. However, hypopnoea scoring based on nasal pressure changes alone would have scored one patient as normal $\left(\mathrm{A}+\mathrm{H} \mathrm{fl}: 7 \cdot \mathrm{h}^{-1}\right.$ in bed) who had an $\mathrm{A}+\mathrm{H}>15 \cdot \mathrm{h}^{-1}$ both on polysomnography and on manual Embletta scoring, when hypopnoeas were defined on both thoraco-abdominal and nasal pressure changes.

Home study. On the basis of the synchronous study, the authors categorised the results of the Embletta manual scoring as "OSAHS" $\left(\geqslant 20(\mathrm{~A}+\mathrm{H}) \cdot \mathrm{h}^{-1}\right.$ in bed $)$, "possible OSAHS" $\left(10-20(\mathrm{~A}+\mathrm{H}) \cdot \mathrm{h}^{-1}\right.$ in bed) or "not OSAHS" $\left(<10(\mathrm{~A}+\mathrm{H}) \cdot \mathrm{h}^{-1}\right.$ in bed $)$. On this basis, 21 of the 22 patients with OSAHS $\left(\geqslant 20(\mathrm{~A}+\mathrm{H}) \cdot \mathrm{h}^{-1}\right.$ in bed on manual Embletta scoring) had AHI $\geqslant 15$ on polysomnography, the 22nd patient having an AHI of $13 \cdot \mathrm{h}^{-1}$. All 10 patients categorised as not OSAHS had $\mathrm{AHI}<15$, while three of the seven patients with possible OSAHS had AHI $\geqslant 15$ (AHI: 17, 21 and $30 \cdot \mathrm{h}^{-1}$ slept). This categorisation was then used for the home study results.

The mean difference (polysomnography-Embletta) in $(\mathrm{A}+\mathrm{H}) \cdot \mathrm{h}^{-1}$ in bed was $3 \pm 13 \cdot \mathrm{h}^{-1}(\mathrm{p}=0.06$; fig. $2 \mathrm{a}$ and b) with a good correlation (rho $=0.74, p<0.001)$. In comparison to the polysomnographic $\mathrm{AHI} \cdot \mathrm{h}^{-1}$ slept, the Embletta $(\mathrm{A}+\mathrm{H}) \cdot \mathrm{h}^{-1}$ in bed differed by a mean of $6 \pm 14 \cdot h^{-1}(p=0.006$; fig. $2 c$ and $d)$.

All nine patients with home $\mathrm{A}+\mathrm{H}<10 \cdot \mathrm{h}^{-1}$ in bed had an AHI $<15 \cdot h^{-1}$ slept on polysomnography (median $9 \cdot h^{-1}$, range $\left.4-14\right)$ and all 23 with $>20(\mathrm{~A}+\mathrm{H}) \cdot \mathrm{h}^{-1}$ in bed Embletta had an AHI $\geqslant 15$ on polysomnography. Eighteen of the 50 patients had home studies in the range of $10-20(\mathrm{~A}+\mathrm{H}) \cdot \mathrm{h}^{-1}$ in bed, of whom three had AHI $<15\left(10,14\right.$ and $14 \cdot h^{-1}$ slept $)$ and $15 \mathrm{AHI} \geqslant 15 \cdot \mathrm{h}^{-1}$ slept on polysomnography (median $21 \cdot \mathrm{h}^{-1}$, range $15-57$ ). Twelve of the 50 patients had $\geqslant 5$ periodic limb movements per hour slept (range 5-218) during their in-lab study.

To obtain a criterion for the Embletta-based diagnosis of OSAHS, the agreement on the classification of the patients into groups was evaluated. There was good agreement between the outcomes of the

Table 2. - Polysomnography and limited Embletta studies during the prospective study

\begin{tabular}{lcccrrr}
\hline Patient group & Patients $n$ & PSG $h$ & Emb & PSG:AHI & PSG:A+H & Emb:A+H \\
\hline Emb:A+H & 50 & $7.8 \pm 0.1$ & $6.5 \pm 0.3$ & $29.2 \pm 2.7$ & $27.0 \pm 2.5$ & $23.5 \pm 2.6$ \\
$\mathrm{~A}+\mathrm{H}<10$ & 9 & $7.7 \pm 0.1$ & $5.5 \pm 0.9$ & $9.8 \pm 1.7$ & $9.8 \pm 1.6$ & $5.5 \pm 3.0$ \\
$10 \leqslant \mathrm{~A}+\mathrm{H}<20$ & 18 & $7.7 \pm 0.1$ & $5.7 \pm 0.5$ & $22.4 \pm 2.4$ & $22.0 \pm 2.6$ & $15.6 \pm 2.5$ \\
$\mathrm{~A}+\mathrm{H} \geqslant 20$ & 23 & $7.9 \pm 0.1$ & $6.9 \pm 0.4$ & $42.5 \pm 4.0$ & $38.2 \pm 3.2$ & $37.1 \pm 3.9$ \\
\hline
\end{tabular}

Data are presented as mean $\_$SEM. PSG: polysomnography; Emb: Embletta; AHI: apnoea/hypopnoea index; A+H: apnoea+hypopnoea. 

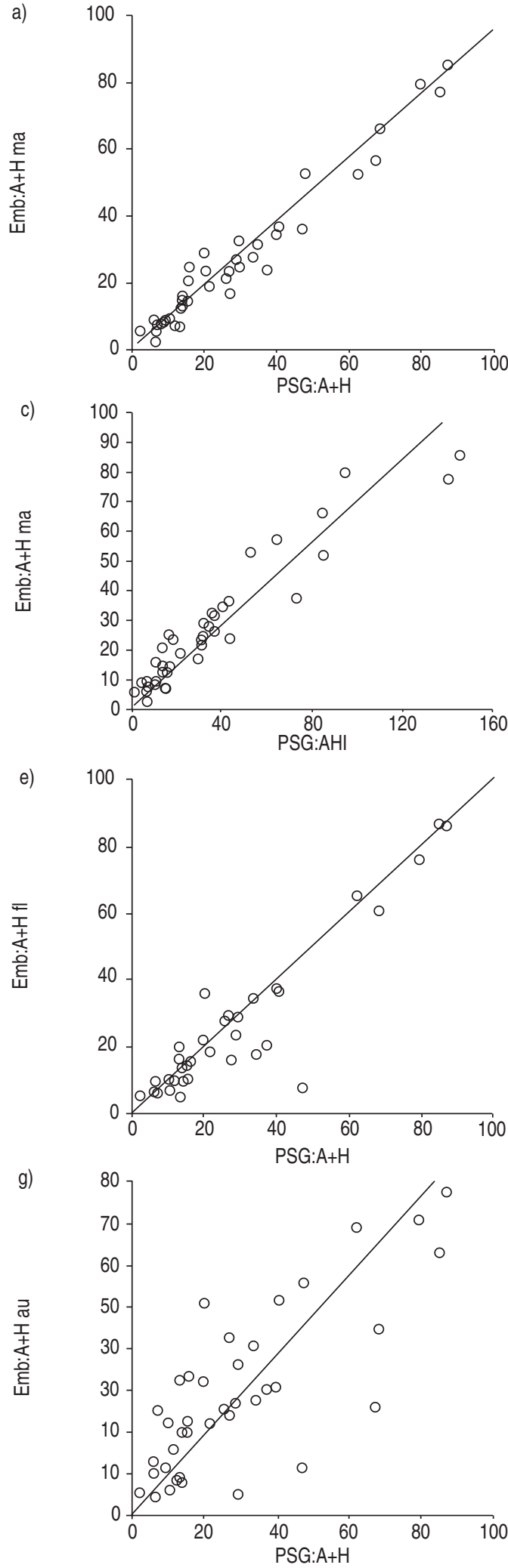
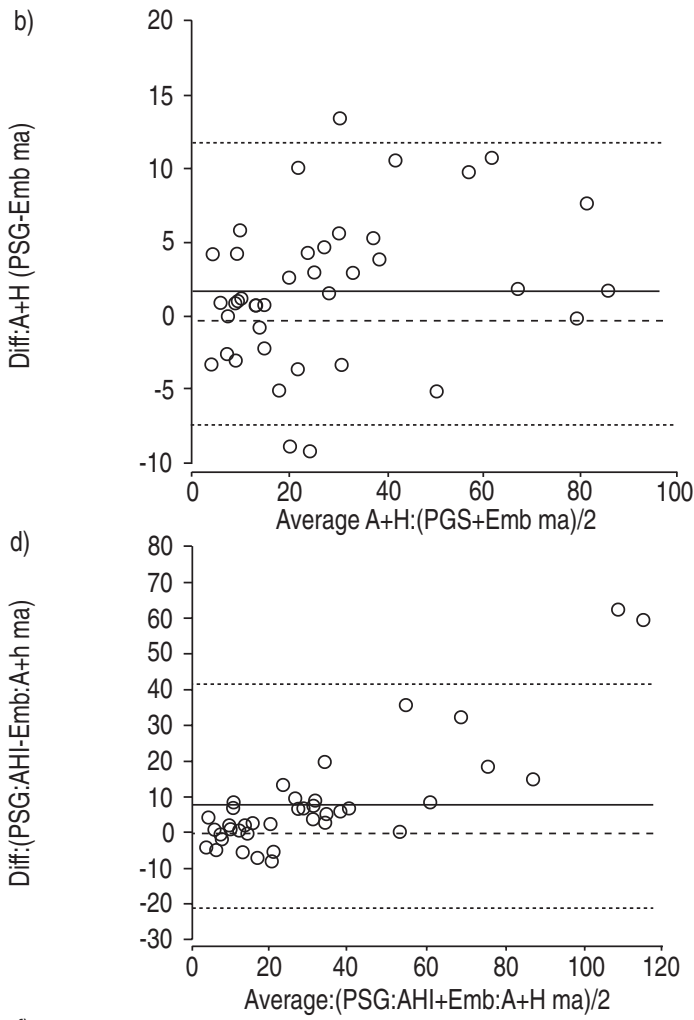

f)
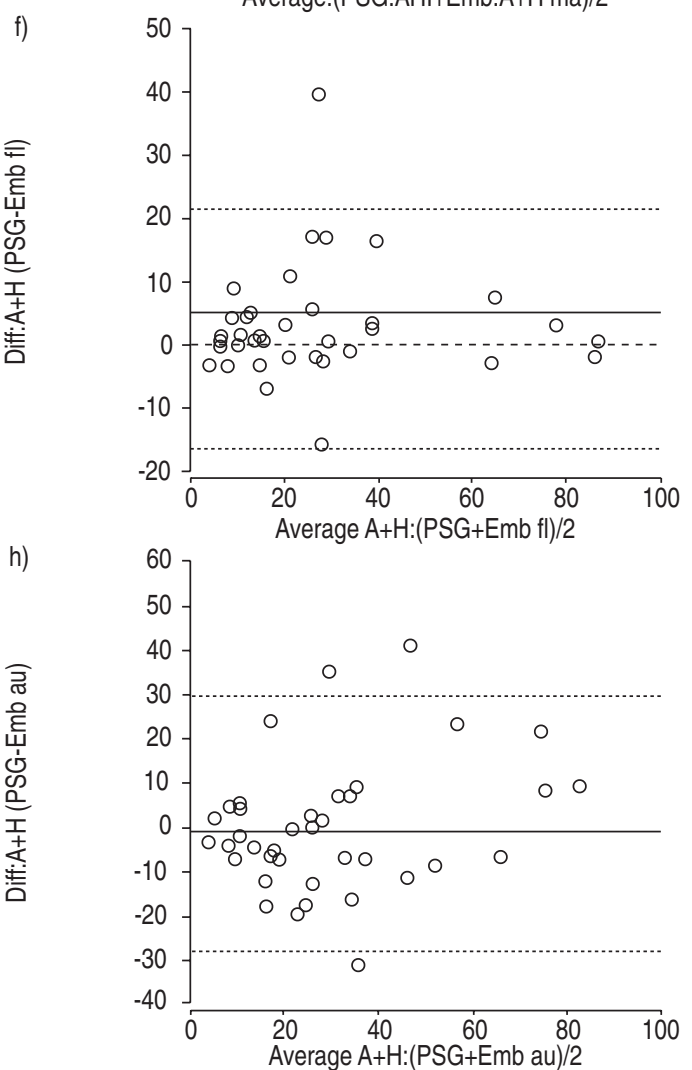

Fig. 1.-Scatterplots with line of identity (a, c, e, g) and Bland and Altman plots (b, d, f, h) across the 39 patients of the prospective trial, between the following. a) and b) Emb:A+H ma: manual apnoea and hypopnoea Embletta score per hour in bed (hypopnoea score is based on nasal pressure and thoracoabdominal changes); and PSG:A+H: polysomnographic apnoea and hypopnoea score per hour in bed. c) and d) Emb:A+H ma: manual apnoea and hypopnoea Embletta score; and PSG:AHI: polysomnographic apnoea and hypopnoea score per hour slept. e) and f) Emb:A+H fl: manual apnoea and hypopnoea Embletta score per hour in bed (hypopnoea score is based on nasal pressure changes alone); and PSG:A+H: polysomnographic apnoea and hypopnoea score per hour in bed. g) and h) Emb:A+H au: automated apnoea and hypopnoea score of Embletta software; and PSG:A+H: polysomnographic apnoea and hypopnoea score per hour in bed. - : mean; $\cdots \cdots \cdot \ldots$ : \pm 1.96 SD. 

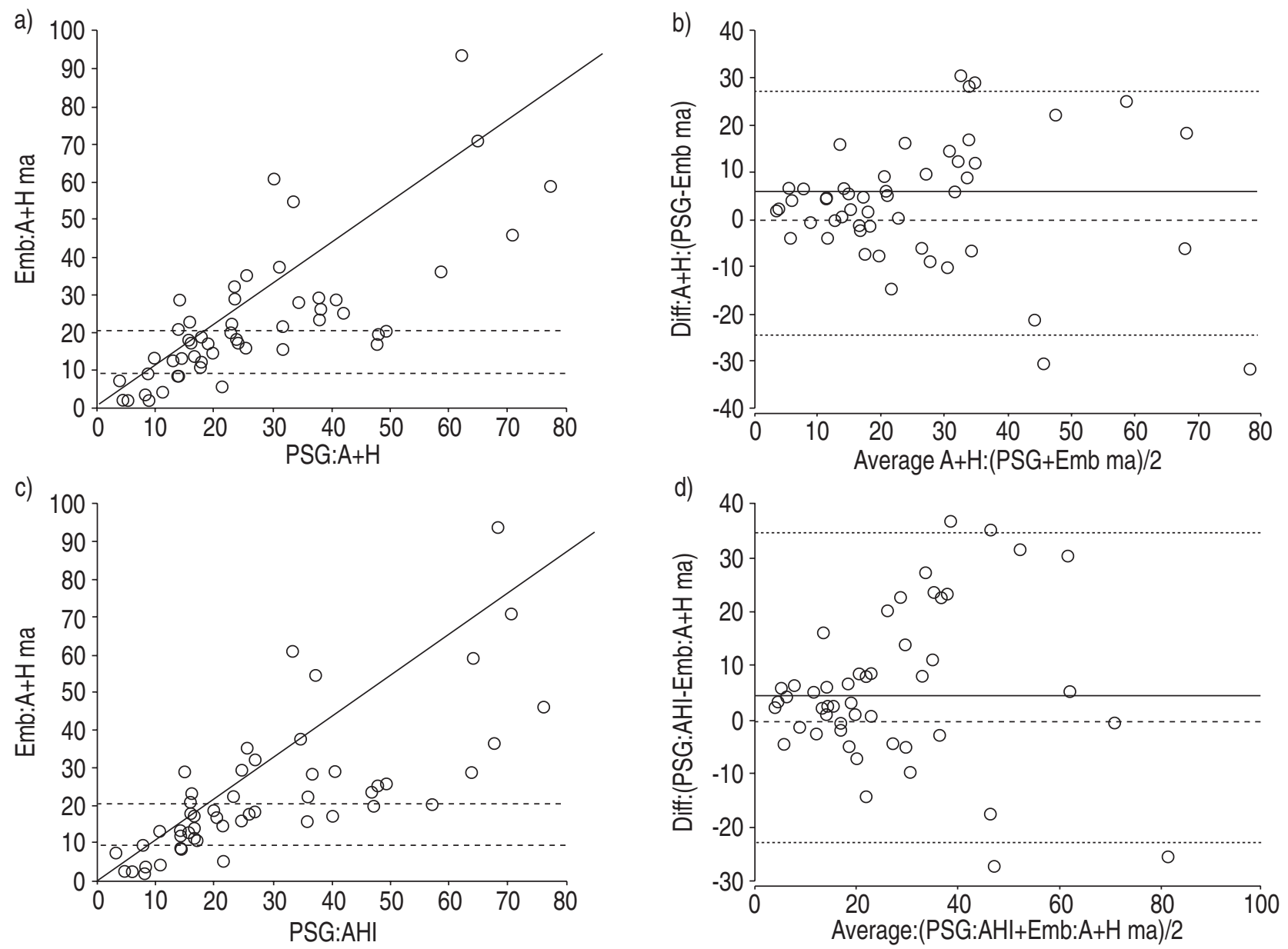

Fig. 2.-Scatterplots with line of identity (a and c) and Bland and Altman plots (b and d) across the 50 patients of the prospective trial between the following. a) and b) Emb:A+H ma: manual apnoea and hypopnoea Embletta score per hour in bed (hypopnoea score is based on nasal pressure and thoracoabdominal changes); and PSG:A+H: polysomnographic apnoea and hypopnoea score per hour in bed. c) and d) Emb:A+H ma: manual apnoea and hypopnoea Embletta score; and PSG:AHI: polysomnographic apnoea and hypopnoea score per hour slept. —: mean; …...: \pm 1.96 SD.

limited recordings and polysomnography in the synchronous studies (kappa coefficient: 0.62; $\mathrm{p}<0.001$ ). The agreement between outcomes based on nasal pressure changes only and polysomnography was also good (kappa coefficient: 0.57 ; $\mathrm{p}<0.001$ ). The homebased studies showed an overall good agreement with the polysomnographic outcomes (kappa coefficient: $0.54 ; \mathrm{p}<0.001)$. During both the synchronous and home studies, agreement between polysomnography and automated Embletta software analysis was poor (table 3).

\section{Discussion}

This study shows that home recording with the Embletta device can produce clinically useful results. On the basis of the three diagnostic bands determined from the synchronous study, all 32 of the 50 patients in the home study who fell into a clear diagnostic category were correctly categorised. It must be stressed that these categorisations were determined before the home study results were examined. However,
18 of the 50 patients fell into the possible OSAHS category in which further study might be indicated. As 15 of these had AHIs on polysomnography of $\geqslant 15$, further studies might be indicated to determine whether a lower $(\mathrm{A}+\mathrm{H}) \cdot \mathrm{h}^{-1}$ in bed on home studies could be regarded as diagnostic for OSAHS.

The analysis is critically dependent on the definition of OSAHS used. The current authors used a conservative cut of an AHI of $15 \cdot \mathrm{h}^{-1}$ plus symptoms, as there is robust evidence for the benefits of continuous positive airway pressure (CPAP) therapy in symptomatic patients with AHI $\geqslant 15 \cdot h^{-1}[13,14]$. Had the current authors used an AHI of $5 \cdot h^{-1}$ as cut-off [15], then 48 of the 50 patients in the consecutive study reached this threshold and their Embletta results ranged from $2-94 \cdot \mathrm{h}^{-1}$ in bed. However, as diagnostic and treatment decisions should not be slavishly based on any single number derived from an overnight study, the above type of analysis where absolute numbers are regarded as critical can demonstrate "inaccuracies" in categorisation, which are in fact of little importance if a more flexible approach to diagnosis is used. If the authors had used a diagnostic 
Table 3. - Evaluation of diagnostic accuracy of the portable Embletta device using kappa statistics

Kappa coefficient value p-value

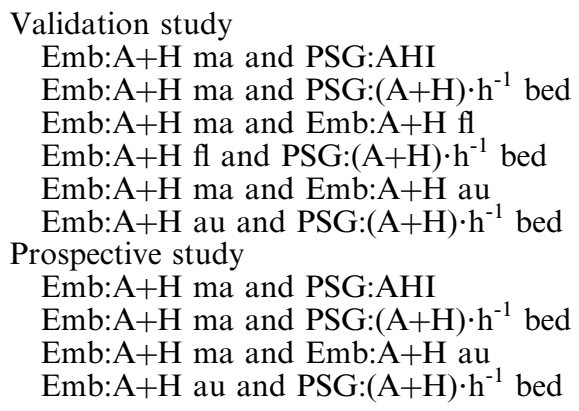

0.62

0.62

0.69

0.57

0.35

0.28

0.50

0.54

0.17

0.10

\section{$<0.001$}

$<0.001$

$<0.001$

$<0.001$

0.003

0.01

$<0.001$

$<0.001$

0.03

0.16

Emb:A+H ma: apnoeas and hypopnoeas score of manual Embletta scoring per hour in bed (hypopnoea score is based on nasal pressure and thoraco-abdominal changes); PSG:AHI: polysomnographic apnoeas and hypopnoeas score per hour slept; PSG:(A+H) $h^{-1}$ bed: polysomnographic apnoeas and hypopnoeas score per hour in bed; Emb:A $+\mathrm{H}$ fl: apnoeas and hypopnoeas score based on manual Emletta scoring per hour in bed (hypopnoea score is based on nasal pressure changes alone); Emb:A+H au: apnoeas and hypopnoeas score of automated Embletta software analysis.

cut-off of $>15(\mathrm{~A}+\mathrm{H}) \cdot \mathrm{h}^{-1}$ in bed on the Embletta, all 34 patients with $>15(\mathrm{~A}+\mathrm{H}) \cdot \mathrm{h}^{-1}$ on the Embletta also had a polysomnography $\mathrm{AHI}>15$. Of the 16 with $<15(\mathrm{~A}+\mathrm{H}) \cdot \mathrm{h}^{-1}$ on the Embletta, three had AHI on polysomnography $>15$ and in the range $16-21 \cdot \mathrm{h}^{-1}$. Thus post hoc alternative cut-offs could be chosen but their value would need to be tested by further study.

Limitations of this study include the number of subjects studied and the venue of the studies. The purpose of the synchronous study was to indicate the accuracy of the device against the alleged "gold standard" of polysomnography. The authors believe that 39 patients are sufficient to demonstrate the broad agreement and the limitations of this approach. The main part of the study with the larger number of patients was testing the device in the location in which it will be mainly used, at home. It is always debatable whether to perform the synchronous study in the home or sleep laboratory environment. A new device to be used at home must be tested both synchronously with polysomnography, in either the home or laboratory setting, and then tested in the home against in-laboratory polysomnography. In-laboratory polysomnography is the appropriate comparator as this is the location where diagnostic studies are most commonly performed and is the nearest to a gold standard that exists. Had the study been limited to synchronous home based polysomnography versus Embletta testing, there would be no comparison with the standard diagnostic test of in-laboratory polysomnography, this was particularly important as there are sleep quality differences between polysomnography at home or in-lab [8]. One of the causes of the bigger variance between Embletta and polysomnography results in the home versus laboratory study (SD $\left.13 \cdot \mathrm{h}^{-1}\right)$ in comparison to synchronous study (SD $\left.5 \cdot \mathrm{h}^{-1}\right)$ is night-to-night variation, which is significant in OSAHS [16]. Another limitation of the study was that this data set encompassed the present authors' early experiences using the Embletta. This is manifest by the high initial fail rate of the home studies (six of 21), as the instruction and education package for the patients was refined. The latter two-thirds of the home study were much more successful with only five of 42 fails. Nevertheless, the overall home diagnostic fail rate of the current study is very similar to that in other studies on base recording; for example, also $18 \%$ in a previous study from the same centre using other equipment [7]. While this learning effect has influenced the success of the home studies, it will not have affected their accuracy.

The utility of this device to sleep centres will depend on local factors, including the relative costs and availability of sleep centre diagnostic studies, the use made of "split night studies", which combine diagnostic studies with CPAP titration in the same night, the geographical spread of the patients investigated, and whether the equipment is attached by the patient or a technician. The device is suitable for use in the patient's home or can be used in hospital to study patients admitted for investigation of OSAHS or those already admitted in whom the question of OSAHS is then raised. In the mode used in the sequential study with the diagnostic categories chosen, the present authors estimate that in comparison to performing overnight sleep centre diagnostic polysomnographies in all patients, the use of home Embletta studies reduce diagnostic costs by $42 \%$ if those in the diagnostic categories went straight to CPAP titration or to no further investigation with only those in the possible OSAHS and failed home study groups proceeding to polysomnography. This is calculated on the basis of the centre's costs of $£ 250$ for each polysomnography (including charge for accommodation, equipment write down, technician and nurse time, and disposables) and $£ 29$ for an Embletta study, this comprising $2 \mathrm{~h}$ of technician time to prepare the device, educate the patients on its application and score each Embletta recording manually, £6 for disposables and write down of the $£ 5,800$ purchase price of an Embletta over 5 yrs with five studies per week over that period. Thus, use of the Embletta in the mode described is cost effective.

The study also suggests that use of the nasal pressure signal as the sole indicator of hypopnoeas will result in unscorable traces in $\sim 8 \%$ of studies. Thus, the authors recommend the use of both the 
nasal pressure and the thoraco-abdominal movement as indicators of hypopnoeas, at least until further data are available. The automatic scoring software did not relate closely to the manually scored results. This could, perhaps, be a problem with the present criteria in the software rather than a fundamental flaw.

Thus, the Embletta as used in this study can save both costs and sleep laboratory usage in the diagnosis of obstructive sleep apnoea/hypopnoea syndrome.

\section{References}

1. Young T, Palta M, Dempsey J, Skatrud J, Weber S, Badar S. The occurrence of sleep-disordered breathing among middle-aged adults. $N$ Engl J Med 1993; 328: $1230-1235$.

2. Teran-Santos J, Jiménez-Gómez A, Cordero-Guevara J. Co-operative Group Burgos-Santander. The association between sleep apnoea and the risk of traffic accidents. N Engl J Med 1999; 340: 847-851.

3. Nieto FJ, Young TB, Lind BK, et al. Association of sleep-disordered breathing, sleep apnoea, and hypertension in a large community-based study. Sleep Heart Health Study. JAMA 2000; 283: 1829-1836.

4. American Academy of Sleep Medicine Task Force Report. Sleep-related breathing disorders in adults: recommendations for syndrome definition and measurement techniques in clinical research. Sleep 1999; 22: 667-689.

5. Kapur V, Blough DK, Sandblom RE, et al. The medical cost of undiagnosed sleep apnoea. Sleep 1999; 22: 749-755.

6. Bahammam A, Delaive K, Ronald J, Manfreda J, Roos L, Kryger MH. Health care utilization in males with obstructive sleep apnoea syndrome two years after diagnosis and treatment. Sleep 1999; 22: 740-747.

7. Whittle AT, Finch SP, Mortimore IL, MacKay TW,
Douglas NJ. Use of home sleep studies for diagnosis of the sleep apnoea/hypopnoea syndrome. Thorax 1997; 52: 1068-1073.

8. Kingshott RN, Douglas NJ. The effect of in-laboratory polysomnography on sleep and objective daytime sleepiness. Sleep 2000; 23: 1109-1113.

9. Whyte KF, Allen MB, Jeffrey AA, Gould GA, Douglas NJ. Clinical features of the sleep apnoea/ hypopnoea syndrome. $Q J$ Med 1989; 72: 659-666.

10. Douglas NJ, Thomas S, Jan MA. Clinical value of polysomnography. Lancet 1992; 339: 347-350.

11. Rechtschaffen A, Kales A, eds. A manual of standardised terminology, techniques and scoring systems for sleep stages of human subjects. Publication No: 204. Washington DC, National Institutes of Health, 1968.

12. Norman RG, Ahmed MM, Walsleben JA, Rapoport DM. Detection of respiratory events during NPSG: nasal cannula/pressure sensor versus thermistor. Sleep 1997; 20: 1175-1184.

13. Engleman HM, Martin SE, Kingshott RN, Mackay TW, Deary IJ, Douglas NJ. Randomised placebo controlled trial of daytime function after continuous positive airway pressure (CPAP) therapy for the sleep apnoea/hypopnoea syndrome. Thorax 1998; 53: 341-345.

14. Engleman HM, Martin SE, Deary IJ, Douglas NJ. Effect of continuous positive airway pressure treatment on daytime function in sleep apnoea/hypopnoea syndrome. Lancet 1994; 343: 572-575.

15. American Academy of Sleep Medicine Task Force Report. Sleep-related breathing disorders in adults: recommendations for syndrome definition and measurement techniques in clinical research. Sleep 1999; 22: 667-689.

16. Wittig RM, Romaker A, Zorick FJ, Roehrs TA, Conway WA, Roth T. Night-to-night consistency of apneas during sleep. Am Rev Respir Dis 1984; 129: 244-246. 